\title{
Multiple Theme in English and Persian
}

\author{
Mohsen Khedri \\ Ph.D Candidate in Applied Comparative Linguistics, University Putra Malaysia, Malaysia \\ Email: Khedri295@yahoo.com \\ Seyed Foad Ebrahimi \\ Department of English, Shadegan Branch, Islamic Azad University, Shadegan, Iran \\ Email: Seyedfoade@yahoo.com
}

\begin{abstract}
The present paper addressed thematicity in academic texts between English and Persian aiming to see how Persian translators tackle thematic structure especially multiple theme and its subtypes, textual and interpersonal themes, and what may happen to these features when a text goes through a translation process. Unfortunately, few studies have been done in the area of how thematic structure is appeared in different languages. The gap is felt more when it comes to the comparison between English and Persian. Therefore, following Halliday's (1994) taxonomy, this study tried to investigate and compare these cohesive devices used in English and Persian academic texts. To this end, the first three pages of the first chapters of 8 English books in the field of teaching and their translation versions were selected. Results indicated that there were significant differences between the languages in focus regarding multiple theme.
\end{abstract}

Index Terms - thematic structures, thematic organization, multiple theme, translation

\section{INTRODUCTION}

While explaining something to another person, whether in speech or writing, we try to organize what we say in a way that makes it easier for the reader to understand (Bloor and Bloor, 1995). The structuring of language as a message is realized in the thematic structures of the consistuent clauses of a text. Theme/rheme play a major role in organizing the message and in enabling it to be communicated and understood clearly (Halliday, 1994). As Ventola (1995) states, there is no question about the usefulness of these analytical devices-thematic structures. This area is a fruitful one if investigated extensively ( $\mathrm{p}$ 85). She also points out that "what is needed by is a more thorough investigation of the theme/rheme issues and the role they play in creating textuality and cohesion in texts" (p. 102).

Taking the importance of thematic structures in creating a more cohesive text into account, it requires shedding more light on the role of thematicity, but in translation. This means that to see what happens to the theme types and how they are tackled by translators when the text goes through a translation process. Making any unmotivated and unreasonable change into them may cause difficulties in conveying the intended meaning of source text's author and then getting readers into great troubles since thematic structures and progression may be quite different among various languages. In this line, Baker (1992 as cited in Munday, 2001) asserts that thematic structures are realized differently in different languages (p. 97).

Fries (1995) also states that systemic theory predicts that every language will have some grammatical function which serves to mark the point of departure for the clause (or other grammatical units) as message. Moreover, one would predict that although there will be a general similarity across languages in the functions of thematic material, the specific uses to which that material is put in the various languages of the world will differ (p. 1).

Ventola (1995) mentions that the translation choices by translator do not follow and display the same rhetorical principles and effects as the author's original text. The translator changes the thematic structure of the clauses. Consequently, he/she will succeed, to some extent, in displaying the unfolding of the global structure of the text in the translated version (p. 98).

The notion of thematicity has been discussed widely in linguistic literature, especially within Prague School of linguistics and systemic-functional theory. Various scholars have in recent years contributed to the study of textuality of texts by analyzing their theme, thematic structure, and thematic progression in text across different languages (Belmonte \& McCabe, 2001; Green, Christopher, and Mei, 2000; Hasselgard, 2004; Khedri, 2008; Khedri \& Ebrahimi, 2012; McCabe, 1999; Ventola, 1995; Williams; 2005) to find out how academic texts unfold thematically.

Ventola (1995) carried out a study in which she compared the role of thematic structure in German philosophy texts produced by German authors and their parallel texts in English, their translation. McCabe (1999) compared the thematic patterning in both English and Spanish history textbooks. She analyzed the ideational, textual, and interpersonal themes in both corpora and concluded that the similarity in content, purpose and audience results in texts which show similarities in textual features. Hasselgard (2004) worked on thematic structures in 1200 sentences in English and their translation in Norwegian. She found that there were significant differences between these two languages regarding the grammatical structure of sentence openings. Williams (2005) performed the analysis of thematic items referring to 
research and researchers in the discussion section of Spanish biomedical articles and English-Spanish translation. And applying Halliday's (1994) thematic organization and McCabe's (1999) thematic progression, Khedri (2008) scrutinized thematic development and progression in English academic texts and their translations in Persian.

Even though many studies have been done on the role and function of thematic structures in translation, work on the status of theme between/among different languages is still extremely low. The gap is felt more when this scarcity comes to the status of theme in English and Persian languages. As pointed out by Ventola (1995), an area that is relatively unexplored is what happens to the texts' thematic organization and their thematic progression when the text goes through a translation process (p. 85). Therefore, this paper was put forward to scrutinize multiple theme, as an essential theme from the cohesion perspective (Hasselgard, 2000), in English academic texts and their counterparts in Persian. The reason behind putting multiple theme in focus are threefold: 1) it may contain several cohesive elements at the same time as it signals the thematic perspective of the sentence in producing cohesive text (Hasselgard, 2000), 2) it overlaps with thematic progression in so far as it frequently links a clause to the proceeding clause (Hawes \& Thomas, 1997) and 3) it is a useful guide to the rhetorical path that the writer is following (Bloor \& Bloor, 1995).

\section{METhodology}

\section{A. Unit of Analysis}

Different researchers have selected different grammatical units to study theme, according to their purposes. For Halliday, the basic unit for thematic analysis is the clause, for Whittaker, orthographic sentences, for McCabe, independent conjoinable clause complex or T-unit. For the purpose of this research, T-unit was adopted as the unit of analysis. Fries (1994) defined T-unit as "an independent clause together with all hypotactically related clauses which are dependent on it" (p. 229). The rationale behind this selection was that:

"Analyzing theme at the level of t-unit rather than the individual clause makes it easier to focus on patterns of thematic development in large amounts of text, and can also be justified on the grounds that the thematic structure of a dependent clause is often constrained by the independent clause. (Fries \& Francis, 1992 as cited in North, 2005).”

\section{B. Text Selection}

The corpus used in this study limited to sample academic texts that were selected from the first three pages of the first chapters of 8 books in the field of teaching ( 4 in English and 4 in Persian). The selection was done with the aim of building a corpus representative of those books taught in the Iranian universities at BA and MA levels and translated into Persian. The corpus was divided into two subcorpora: sample academic texts in English and sample academic texts in Persian. The Persian texts were the translated versions of the same English texts. The obtained corpus contained 11606 words (5682 for English and 5924 for Persian). There were some reasons behind this selection. The first reason was that the first chapter of a book is usually its point of departure. The second one was to maintain the consistency of thematic progression among paragraphs in each text and avoid invalid judgment of thematicity. The third reason was that the texts chosen represented a variety of authors and translators. And the last one was, it appeared that this quantity was enough to allow the researcher to arrive at valid generalizations.

\section{Instruments}

In order to achieve a well-organized study, complete model is required for analyzing the data. The theoretical and analytical framework for this study in terms of thematic organization was one suggested by Halliday (1994). The major rationale behind the selection of the selected model was twofold: 1) as Martinez (2003, p. 108) mentions, the model in focus provides plausible and attestable mechanisms for determining the thematic structures of the texts correctly; 2) It is practical, reliable, and up-to-date model. Most of the studies that have been done in terms of thematic analysis have resorted to this model.

\section{Procedure}

The procedure applied in this study was firstly, the selection of sample texts from the first three pages of the first chapters of 8 books in the field of teaching. These sample texts were in English and their translations in Persian. Secondly, the texts, both original and translated versions, were compared and contrasted according to the above mentioned model to determine their multiple theme and its subthemes. Thirdly, the relationship between thematic organization (in this study, textual, interpersonal, and multiple themes) of the selected academic texts was investigated. Finally, the data was analyzed to scrutinize the similarities and differences that would exist in English and Persian languages concerning the above mentioned theme types. One problem with textual analysis of texts is that there is always the danger of making mistakes in interpretation. To avoid the threat of reliability in the analysis, the first three pages of one book in both languages from the corpus were also analyzed by an experienced researcher in the field of teaching and agreement was made on the method of analysis.

\section{E. Data Analysis}

To analyze the texts in the present study quantitatively, the frequency of different theme types (textual, interpersonal, and multiple) was calculated. Next, Chi-square as a significance test was employed to compare and contrast the 
obtained frequencies to see the statistically significant differences. In sum, the data were analyzed using the statistics software SPSS (Statistics Package for Social Sciences).

\section{RESULT AND DISCUSSION}

Multiple theme consists of textual or interpersonal or both beside the topical theme (Halliday, 1994). Concerning multiple themes, the frequency and percentage of textual and interpersonal theme types were calculated and displayed in table 1.

TABLE1.

FREQUENCY ANALYSIS AND PERCENTAGE OF TEXTUAL AND INTERPERSONAL THEMES

\begin{tabular}{|l|l|l|}
\hline & English (\%) & Persian (\%) \\
\hline Textual & $45(16.18)$ & $91(29.16)$ \\
\hline Interpersonal & $12(4.32)$ & $12(3.84)$ \\
\hline
\end{tabular}

As it is quite clear, textual theme was applied in both corpora more than interpersonal theme. This is in line with Ghadessy's (1995; 1999), North's (2005), and Whittaker's (1995) results. Whittaker (1995) points out that this result is not surprising because scientific text tends to be impersonal and objective; moreover, the purpose of its writer is to persuade reader to read it (p. 109). She also argues that textual themes help the reader follow the organization of the argument of the text (p. 113), hence their greater inclusion.

Interestingly, the number of textual theme used in Persian translated texts was twice more than that applied in English original texts totaling $29.16 \%$ and $16.18 \%$ in respective languages. This means the greater tendency of translators in the application of textual theme resulting in the argumentative, impersonal, and factual tone of texts in Persian compared to that in English employing plenty of conjunctions and conjunctives functioning as textual theme to link each clause to the surrounding text and context (McCabe, 1999). The greater reliance of Persian translators, at least in the present research, made their translations be persuasive for the readers to follow the flow of information in a smoother way (Ghadessy, 1999). This result seemed to be in contrast to McCabe's (1999) results. She found the identically total number of textual themes in her corpus, English and Spanish history texts, 23.40\% textual theme in English and $23.91 \%$ in Spanish.

Regarding interpersonal theme, as shown in table 1, this sort of theme was used with an identical number in both text types. It is worthy to point out that this similarity can be justified in terms of genre. To Halliday and Hasan (1985), texts belonging to the same genre represent a similar contextual configuration, that is, they show common characteristics in terms of field, mode, and tenor of discourse. Similarities in field, tenor, and mode engender similarities in textual choices and are reflected in the thematic choices preferred since the field, tenor, and mode can be realized in topical, interpersonal, and textual themes respectively. Therefore, theme as one of the textual choices provides interesting insight into establishing similarities within and between genre(s). This is in line with studies conducted by such researchers as Ghadessy (1995, 1999), North (2005), and Whittakar (1995). In their own words, different types of theme can reveal crucial characteristics of the texts regarding genre.

The frequency and percentage of different kinds of textual and interpersonal themes were clarified and compared in both English and Persian languages. Textual theme was analyzed in term of its theme types (conjunction, conjunctive adjunct, and continuative) and the results of the frequency and Chi-square analyses are illustrated in tables 2 and 3.

The data analysis illustrated that textual theme types with the exception of continuative that not used at all in both corpora, conjunction was employed more than two times in Persian in expense to English (71 cases and 33 cases in respective languages) and conjunctive adjunct was applied roughly two times by Persian translators compared to English authors totaling 20 tokens and 12 tokens respectively. Amongst all textual theme types, the most frequently used element was conjunction. The result agreed with McCabe's (1999), North's (2005), and Whittaker's (1995) findings. McCabe (1999) found that the most frequent type of textual theme used in English history textbooks was conjunction. Halliday (1994) states that conjuction is an item which relates a clause to the preceding clause in the same sentence or the same clause complex while conjunctive adjunct is that which relates a clause to the preceding text. Conjunction is similar in meaning to conjunctive adjunct but they differ in that, while conjunctive adjunct sets up a semantic relationship with what precedes, conjunction sets up a relationship which is semantic and grammatical simultaneously. It constructs the two parts into a single unit. So, it seems that this kind of textual theme is more important in comprehending and creating cohesive texts. Therefore, texts in Persian appeared to be more cohesive resulting from the over-use of conjunction. Concerning continuative, it was neglected in both text types. Such an event can be explained and justified regarding Halliday's (1994) definition. He contends that "continuative is a discourse signaler that shows a new move is beginning in the dialogue or a move to the next point if the same speaker is continuing". Thus, continuative is generally signaler of spoken discourse rather than written discourse.

In addition, the results of Chi-square analysis, as indicated in table 3, revealed that there was statistically significant difference between source texts and target texts only in terms of conjunction. This results in producing more cohesive translated texts in Persian. 
TABLE 2.

FREQUENCY ANALYSIS AND PERCENTAGE OF TEXTUAL THEME TYPES

\begin{tabular}{|l|l|l|l|}
\hline & English & Persian & \\
\hline & $\mathrm{F}(\%)$ & $\mathrm{F}(\%)$ & Total \\
\hline Conjunction & $33(31.73)$ & $71(68.27)$ & 104 \\
\hline Conjunctive & $12(37.50)$ & $20(62.50)$ & 32 \\
\hline Continuative & 0 & 0 & 0 \\
\hline Total & 45 & 91 & 136 \\
\hline
\end{tabular}

TABLE 3.

CHI-SQUARE ANALYSIS OF TEXTUAL THEME TYPES

\begin{tabular}{|l|l|l|l|l|l|}
\hline & English & Persian & Chi-square & Df & Sig \\
\hline Conjunction & 33 & 71 & 13.885 & 1 & 0.0002 \\
\hline Conjunctive Adjunct & 12 & 20 & 2.000 & 1 & 0.1573 \\
\hline Continuative & 0 & 0 & $*$ & $*$ & $*$ \\
\hline
\end{tabular}

Tables 4 and 5 present the frequency and Chi-square analyses of different kinds of interpersonal theme used by authors and translators respectively. While the most frequent type of interpersonal theme in translated texts was modal adjunct, finite operator was applied more by authors in English texts. Finite operator occurred in a very low proportion and let's was quite neglected compared to modal adjuncts. To Halliday (1994), "modal adjunct expresses the speakers' judgment regarding the relevance of the message". The modal adjunct's high frequency in the corpus was in line with findings gained in McCabe's (1999) study. She found the relative similarity overall across Spanish and English languages, 39 cases or $2.67 \%$ and 40 cases or $3.09 \%$ of modal adjuncts in English and Spanish texts respectively. Following Halliday (1994), finite operator makes the proposition finite and brings it down to earth as it is something that can be argued and make it arguable so it can be concluded that translated texts in Persian were more argumentative in contrast to the original texts in English.

To the results taken from the Chi-square analysis, there was no significant difference between both text types in light of applying interpersonal theme types except in finite operators.

TABLE 4.

FREQUENCY ANALYSIS AND PERCENTAGE OF INTERPERSONAL THEME TYPES

\begin{tabular}{|l|l|l|l|}
\hline & English & Persian & \\
\hline & $\mathrm{F}(\%)$ & $\mathrm{F}(\%)$ & Total \\
\hline Modal & $4(26.66)$ & $11(73.34)$ & 15 \\
\hline Finite & $8(88.88)$ & $1(11.12)$ & 9 \\
\hline Let's & 0 & 0 & 0 \\
\hline Total & 12 & 12 & 24 \\
\hline
\end{tabular}

TABLE5.

CHI-SQUARE ANALYSIS OF INTERPERSONAL THEME TYPES

\begin{tabular}{|l|l|l|l|l|l|}
\hline & English & Persian & Chi-square & Df & Sig \\
\hline Modal & 4 & 11 & 3.267 & 1 & 0.0707 \\
\hline Finite & 8 & 1 & 5.444 & 1 & 0.0196 \\
\hline Let's & 0 & 0 & $*$ & $*$ & $*$ \\
\hline
\end{tabular}

In case of multiple theme, the data were analyzed and compared in both corpora. As results showed, multiple theme was more frequent in translated texts than in original texts. $87(27.89 \%)$ in Persian and $52(18.71 \%)$ in English. The most frequent type of multiple themes in both text types was textual ${ }^{\wedge}$ topical ( 75 cases or $86.20 \%$ in Persian and 40 cases or $76.92 \%$ in English). Though in both corpora this pattern was employed frequently, Persian was in a higher position. This is similar to Gomez's (1994) findings. She found that this pattern which represented $68 \%$ of all multiples was the most common of all. Interestingly, though not found in English original texts, 9 cases or $12 \%$ from 75 cases of the type textual $\wedge$ topical multiple themes in Persian contained more than one textual theme (e.g. textual $\wedge^{\wedge}$ textual $\wedge$ topical, or textual $\wedge^{\wedge}$ textual $\wedge$ textual $\wedge^{\wedge}$ topical).

TABLE 6.

FREQUENCY ANALYSIS AND PERCENTAGE OF MULTIPLE THEME TYPES

\begin{tabular}{|c|c|c|}
\hline & English & Persian \\
\hline & $\mathrm{F}(\%)$ & $\mathrm{F}(\%)$ \\
\hline Textual $^{\wedge}$ topical & $40(76.92)$ & $75(86.20)$ \\
\hline Inter $\wedge$ topical & $7(13.46)$ & $6(6.89)$ \\
\hline Textual $^{\wedge}$ inter ${ }^{\wedge}$ topical & $5(9.62)$ & $5(5.74)$ \\
\hline Inter $^{\wedge}$ textual ${ }^{\wedge}$ topical & 0 & $1(1.17)$ \\
\hline Total & $52(18.71)$ & $87(27.89)$ \\
\hline
\end{tabular}

\section{CONCLUDING REMARKS AND IMPLICATIONS}

Ventola (1995) contends that sometimes readers may find texts fuzzy since they consider some odd thematic 
structures that are not typical of the target language. The fault in these texts is very often placed on the author's failures of argumentation and rhetorical skills; it is presumed that the author's logic is not functioning well and his/her argumentation and rhetorics are seen to fail. But often the original argumentation is clear and well-structured rhetorically in the source text; it is the translation that fails and distorts the argumentative and rhetorical patterns (p. 91).

Bearing such a problem in mind, this study was an attempt to investigate the status of multiple theme as a theme type in English academic texts and their translation in Persian. The main concluding remarks taken from the data analysis, both frequency and Chi-square, are as follows that may have some implications for translation:

1) Focus on theme and rheme structure especially multiple theme at the level of clause can have startling and immediate results in translation. Once the translators know how to properly arrange old and new information, they have gained a powerful tool for managing the original meaning of the text intended by the author. They can consciously and strategically draw on this knowledge to construct more cohesive translated texts.

2) Multiple theme is a highly effective and valuable feature in text cohesion. It enhances connectivity between ideas in the text. The results suggested that our understanding of how texts are created and interpreted would be much poorer without the concept of multiple theme. In translated text, multiple theme plays a key role in guiding the reader through the logical paths constructed by the translator since as results revealed both textual and interpersonal themes were employed in a higher proportion in the translated texts in comparison with those applied in the original versions.

In sum, this study has theoretical and pedagogical implications. From theoretical viewpoint, this study shed light on the status of multiple theme and its subtypes, textual and interpersonal themes, in both Persian and English languages which could be eventually useful in understanding the thematic structure of human language. From educational perspective, translators and those who are interested in translation profession can apply the findings of this study in translating any text type from English to Persian. Being conscious of grammatical structure of each language at least at the level of thematization especially multiple theme can be a useful device for conveying the intended message uttered by source texts' writers. All in all, doing so may lead to creating smoother translated texts and also may help the reader to follow the flow of information in a clear way.

\section{REFERENCES}

[1] Belmonte, I. A. , \& McCabe, A. M. (2001). Theme, transitivity and cognitive representation in Spanish and English written texts. http://www.ucm.es/info/circulo/no7/mccabe.htm (accessed 16/5/2007).

[2] Downing, A. (2001). Thematic progression as a functional resource in analyzing texts. http://www.ucm.es/info/circulo/no5/downing.htm (accessed 9/7/2007).

[3] Bloor, T. , \& Bloor, M. (1995). The functional analysis of English: A Hallidayan approach. London: Arnold.

[4] Fries, P. H. (1994). On theme, rheme and discourse goals. In M. Coulthard (Ed.), Advances in written text analysis (pp. 229249). London: Routledge.

[5] Fries, P. H. (1995). A personal view on theme. In M. Ghadessy (Ed.), Thematic development in English text (pp. 1-19). London: Pinter.

[6] Ghadessy, M. (1995). Thematic development and its relationship to registers and genres. In M. Ghadessy (Ed.), Thematic development in English text (pp. 129-146). London: Pinter.

[7] Ghadessy, M. (1999). Thematic organization in academic article abstracts. Estudios Ingleses de la Universidad Complutense, 7 , 141-161.

[8] Gomez, M. A. (1994). The relevance of theme in the textual organization of BBC news reports. World Journal, 19. 3, $293-305$.

[9] Green, C. F., Christopher, E. R. , Lam, J., \& Mei, K. (2000). The incidence and effects on the coherence of marked theme in interlanguage texts: a corpus based study. Journal of English for Specific Purposes, 19, 99-113.

[10] Halliday, M. A. k. (1994). An introduction to functional grammar. London: Edward Arnold.

[11] Halliday, M. A. K., \& Hasan, R. (1985). Language, context, and text: Aspect of language in a social semiotic perspective. Australia: Deakin University Press.

[12] Hasselgard, H. (2000). The role of multiple themes in cohesion. Contrastive Studies in Syntax. Copenhagen Studies in Language, 25, 1-16.

[13] Hasselgard, H. Thematic choice in English and Norwegian. Functions of Language, 11.2, 187-212.

[14] Hawes, T. , \& Thomas, S. (1997). Problem of thematisation in student writing. RELC Journal, 28, 35-55.

[15] Khedri, M. (2008). Thematization and translation in academic texts: Implications for translation courses. M.A. thesis. Islamic Azad University, Science and Research Center of Ahvaz.

[16] Khedri, M. , \& Ebrahimi, S. F. (2012). The essence of thematic structures in the academic translated texts. Journal of Education and Practice, 3.1, 37-43.

[17] Martinez, I. A. (2003). Aspects of theme in the method and discussion sections of biology journal article in English. Journal of English for Academic Purposes, 2, 103-123.

[18] McCabe, A. M. (1999). Theme and thematic patterns in Spanish and English history texts. http: // www. wagsoft.com/systemics/archive/McCabe.phd (accessed 9/7/2007).

[19] Munday, J. (2001). Introducing translation studies: Theories and applications. London: Routledge.

[20] North, S (2005). Disciplinary variation in the use of theme in undergraduate essays. Journal of Applied Linguistics, 26.3, 431452.

[21] Ventola, E. (1995). Thematic development and translation. In M. Ghadessy (Ed.), Thematic development in English text (pp. 85-104). London: Pinter.

[22] Whittaker, R. (1995). Theme, process and the relation of meaning in academic articles. In M. Ghadessy (Ed.), Thematic development in English text (pp. 105-128). London: Pinter. 
[23] Williams, I. A. (2005). Thematic items referring to research and researchers in the discussion section of Spanish biomedical articles and English-Spanish translation. International Journal of Translation, 51.2, 124-160.

Mohsen Khedri, a PhD candidate in Applied Linguistics, received his BA in English language translation from Arak Islamic Azad University and MA in TEFL from Islamic Azad University Science and Research Branch of Ahvaz, Iran. He has been teaching English for several years at universities, language centers.

Seyed Foad Ebrahimi, a PhD candidate in Applied Linguistics, received his BA in English language translation from Abadan Islamic Azad University and MA in TEFL from Islamic Azad University Science and Research Branch of Ahvaz, Iran. He has been teaching English for several years at universities, language centers. 